\title{
Loss of polar trophoblast during differentiation of the blastocyst of the horse
}

\author{
A. C. Enders, K. C. Lantz, I. K. M. Liu* and S. Schlafke \\ Department of Human Anatomy, School of Medicine and *Department of Reproduction, \\ School of Veterinary Medicine, University of California, Davis, California 95616, U.S.A.
}

\begin{abstract}
Summary. Twelve blastocysts, collected 7-12 days after ovulation (Day 0 ), were examined by light and electron microscopy to investigate the nature of the relationship of the polar trophoblast (Rauber's layer) to the inner cell mass. On Day 7, the polar trophoblast was intact and formed a flattened layer overlying the epiblast cells of the inner cell mass. As blastocysts enlarged to $>1 \mathrm{~mm}$ in diameter, small discontinuities appeared in the polar trophoblast, where epiblast cells intruded onto the surface. At this time, trophoblast cells adhered closely to adjacent and underlying epiblast cells, forming an irregular layer of cells capping the epiblast. With continued increase in blastocyst size, polar trophoblast cells became isolated but maintained their characteristic apical endocytic structures. By Days 10-12, the scattered trophoblast cells showed evidence of deterioration, and vacuoles containing cell debris were common within the epiblast.

It is suggested that polar trophoblast cells become scattered, rather than withdrawing as a unit, because they become more adherent to subjacent epiblast cells than to adjacent trophoblast cells. It is further suggested that most of the isolated cells are eventually phagocytosed by epiblast cells.
\end{abstract}

Keywords: horse; blastocyst; trophoblast; differentiation; inner cell mass

\section{Introduction}

Polar trophoblast (Rauber's layer) overlying the inner cell mass of the blastocyst is not lost in most primates (Enders \& Schlafke, 1986) or in common laboratory rodents, and in the mouse may even be augmented by cells from the inner cell mass (Cruz \& Pedersen, 1985). This layer is commonly lost, however, in carnivores, ungulates, and in other species that have large blastocysts and amnion formation by folding (Mossman, 1937; Hamilton \& Mossman, 1972).

Morulas can be collected from the oviduct of the horse as late as 5.5 days after ovulation, and blastocysts can be found in the uterus at about this same time (Betteridge et al., 1982). Although no cellular attachment to the endometrium occurs until the girdle cells invade the endometrium to form the endometrial cups on Day 37 (Allen et al., 1973), blastocysts usually remain in the same region after Day 15, as visualized by repeated ultrasonography (Ginther, 1983). Consequently, from Day 6 through Day 14, the blastocyst can be recovered from the uterus by non-surgical methods (Oguri \& Tsutsumi, 1972). It has proved possible to use such recovery followed by transfer of embryos to produce successful pregnancy both in normal mares (Imel et al., 1981) and in ovariectomized progesterone-treated mares (Hinrichs et al., 1987). The blastocyst not only expands rapidly during this time (Van Niekerk \& Allen, 1975), but is able to synthesize oestrogens (Heap et al., 1982; Goff et al., 1983). Early in this preimplantation period, the zona pellucida is replaced by an acellular capsule, which varies both in ultrastructure (Flood, 1975; Flood et al., 1982) and in antigenic properties (Bousquet et al., 1987) from the zona pellucida. 
Van Niekerk \& Allen (1975) reported, from a series of intact and sectioned blastocysts, that the polar trophoblast of the horse blastocyst disappeared between Day 9 and Day 14 of pregnancy. Betteridge et al. (1982) have provided data on the increase in size of the conceptus during the first 3 weeks of gestation, Betteridge \& Guillomot (1982) studied the preattached horse embryo by scanning electron microscopy and Flood et al. (1982) described the fine structure of trophoblast from Day 3 to Day 16. Flood et al. (1982) noted that, during the expansion of the blastocyst after Day 6, trophoblast cells varied from columnar to cuboidal, but were not the flattened cells commonly seen in other species. These authors also pointed out that trophoblast cells, in addition to microvilli, had numerous apical coated vesicles, large vacuoles and other evidence of endocytosis.

Non-invasive collection of a series of horse blastocysts was used to obtain material for the present study of the manner in which (a) polar trophoblast cells are displaced, and (b) the epiblast of the inner cell mass comes to occupy a surface position without loss of the integrity of the blastocyst or slowing of the rate of blastocyst expansion. A preliminary report has appeared in abstract form (Enders \& Liu, 1987).

\section{Materials and Methods}

Adult mares were maintained at the Equine Research Laboratory, School of Veterinary Medicine. The ovaries of the mares were palpated via the rectum daily. After detection of a large $(40-50 \mathrm{~mm})$ preovulatory follicle, mares were mated naturally or artificially inseminated daily until ovulation occurred, as determined by palpation of a fresh ('mushy') corpus luteum. The day on which the ovulation was detected was designated Day 0 .

On the day of embryo recovery, a 30-French gauge two-way Foley catheter (Bard Urological, Murray Hill, NJ) with a $70-\mathrm{ml}$ inflatable cuff was inserted through the cervix, and the cuff dilated with sterile saline solution. Four sequential samples (1000 ml each) of sterile Dulbecco's phosphate-buffered saline (Gibco Laboratories, Santa Clara, $\mathrm{CA}$ ) were introduced into the uterine lumen and recovered into an Erlenmeyer flask. The blastocysts were observed initially by transillumination of the recovery flask, and were usually found in the first litre of flushings collected. Blastocysts were then removed, examined and measured using a dissecting microscope. Between Days 7 and 12 after ovulation, 13 embryos were collected: 1 on Day 7; 3 on Day 8; 3 on Day 9; 2 on Day 10; 2 on Day 11 and 2 on Day 12 .

Embryos were fixed in freshly prepared $2 \%$ formaldehyde- $2 \%$ glutaraldehyde in $0 \cdot 1 \mathrm{M}$-phosphate buffer, pH $7 \cdot 3$, for 30-90 min at room temperature. Following an overnight rinse in phosphate buffer at $4^{\circ} \mathrm{C}$, they were post-fixed in $1 \%$ osmium tetroxide in phosphate buffer for 20-60 min, rapidly dehydrated in alcohol, placed in propylene oxide for $10 \mathrm{~min}$, and embedded in Durcupan epoxy resin.

To demonstrate the capacity of trophoblast for pinocytosis of proteins, two exogenous tracers, cationized ferritin and horseradish peroxidase, were used. One intact blastocyst $(1.5 \mathrm{~mm})$ and a portion of trophoblast of one blastocyst $(3.7 \mathrm{~mm})$ were incubated before fixation in cationized ferritin (CF; Miles Laboratories, Naperville, IL) at a concentration of $1 \mathrm{mg} / \mathrm{ml}$ in Earle's basic salt solution (EBSS) for 10 and $20 \mathrm{~min}$. These tissues were rinsed, then fixed and processed for transmission electron microscopy (TEM) as above. Three intact blastocysts (1-2 mm) and portions of trophoblast from 3 blastocysts $(3.7,10$ and $20 \mathrm{~mm}$ ) were incubated in horseradish peroxidase (HRP, Type VI; Sigma, St Louis, MO) at a concentration of $1 \mathrm{mg} / \mathrm{ml}$ in EBSS for $10-20 \mathrm{~min}$. After aldehyde fixation, this tissue was incubated in diaminobenzidine medium for $10 \mathrm{~min}$ to demonstrate the peroxidase activity, rinsed in distilled water, post-fixed in $1 \%$ osmium tetroxide and processed for TEM as described above.

Representative thick sections were obtained until the inner cell mass (ICM) was encountered; then thin sections were made and examined in a Philips 400 or 410 or a Zeiss 10 electron microscope.

Portions of all of the larger blastocysts $(3 \cdot 7-20 \mathrm{~mm})$ were fixed in aldehyde fixative, post-fixed in osmium, dehydrated in acetone and critical-point dried. Tissues were placed on aluminium stubs, then gold coated and examined in a Philips 501 scanning electron microscope.

\section{Results}

\section{Summary of blastocyst development during loss of polar trophoblast}

The blastocyst obtained on Day 7 was $0.4 \mathrm{~mm}$ in diameter; the three from Day 8 measured $1 \cdot 0$, 1.0 and $1.5 \mathrm{~mm}$; those from Day 9 were 2.0, 2.0 and 3.0; those from Day 10 were 3.7 and 4.0 ; and those from Day 11 were 4.5 and $8.0 \mathrm{~mm}$. Consequently, during the period between Day 7 and Day 11 , the blastocyst doubled in diameter every $24 \mathrm{~h}$ while remaining largely spherical. Subsequently, the blastocysts became elongated, and the diameter $(10 \mathrm{~mm}$ and $20 \mathrm{~mm})$ was no longer an accurate 
measure of size increase. The size increases recorded here fit well with published sizes during these stages (Betteridge et al., 1982). Horse blastocysts of $<1 \mathrm{~mm}$ in diameter had a small discoidal inner cell mass (ICM) with a simple covering of low cuboidal trophoblast. Discontinuities appeared in the polar trophoblast during the 1-2 mm stage, and the trophoblast cells became progressively isolated and scattered during the $2-4 \mathrm{~mm}$ stage. Subsequently, only a few trophoblast cells were found over the broadly discoidal ICM, and signs of ingestion of cell material became abundant.

\section{Stage of intact polar trophoblast}

The ICM of the early blastocyst $(0.4 \mathrm{~mm})$ consisted of a small flattened disc of cells within the spherical blastocyst, and was composed of undifferentiated epiblast cells underlain by a layer of endoderm (hypoblast) (Fig. 1). The ICM was covered by a layer of trophoblast, the polar trophoblast (Rauber's layer), which was continuous with the mural trophoblast that surrounded the blastocyst cavity. Superficial to the trophoblast was a uniform acellular membrane, the capsule. Short remnants of the zona pellucida were present on the surface of the capsule of the smallest blastocyst. Small patches of basal laminar material were found subjacent to the epiblast and the mural trophoblast on the interior of the blastocyst. No such accumulations of granular material appeared between the polar trophoblast and epiblast, and these two layers were closely apposed, with the border taking an undulating course as the epiblast conformed to the fusiform outline of the trophoblast cells. The endodermal layer, both where it underlay the epiblast to form the visceral endoderm and where it extended beyond the ICM forming the parietal (mural) endoderm, was loosely associated with the overlying epiblast and trophoblast, and lacked any evidence of a basal lamina.

Polar trophoblast formed a continuous epithelial layer composed of dense, somewhat irregular cells that were generally thicker in the perinuclear region (Fig. 1). The basal surfaces of the trophoblast cells were closely associated with underlying ICM cells with little intervening intercellular space. Polar trophoblast cells contained characteristic large apical vacuoles, coated pits and vesicles, numerous microvilli and polyribosomes. Although these polar trophoblast cells were low cuboidal or occasionally peg-shaped, they were cytologically similar to the mural trophoblast cells as described by Flood et al. (1982).

The large pale cells of the ICM contained a euchromatin-rich nucleus, which in turn enclosed large dense nucleoli. The ICM varied from 1 to 2 cells thick, with no obvious orientation or cellular polarization, and the cells were closely apposed except for small pockets of intercellular space into which numerous microvilli intruded. Polyribosomes were more abundant free in the cytoplasm than in association with short strands of granular endoplasmic reticulum. A few lipid droplets were present.

\section{Initial disruption of polar trophoblast}

In blastocysts $>1 \mathrm{~mm}$ in diameter, the most noted change was the rounding up of the epiblast cells (Fig. 2). The darker polar trophoblast cells were closely adherent to the underlying epiblast cells of the ICM, resulting in a highly irregular border and a peg-shaped outline to many of the trophoblast cells. Furthermore, some of the polar trophoblast cells had processes that not only projected basally between adjacent epiblast cells but extended to the general basal level of the epiblast, giving the latter an interrupted appearance. Close examination revealed that some of the epiblast cells reached the surface of the blastocyst between polar trophoblast cells, producing the first disruption of this layer (Fig. 3). Where such epiblast cells reached the surface, they shared apical junctional complexes with the adjacent polar trophoblast cells, but usually had fewer microvilli than did trophoblast cells and largely lacked vacuoles (Fig. 4).

Junctional complexes were found between epiblast cells, including apparent tight junctions, gap junctions and punctate desmosomes at various levels throughout the epiblast. The epiblast cells were quite closely associated with one another except in the areas of pockets of microvilli (Fig. 5). 


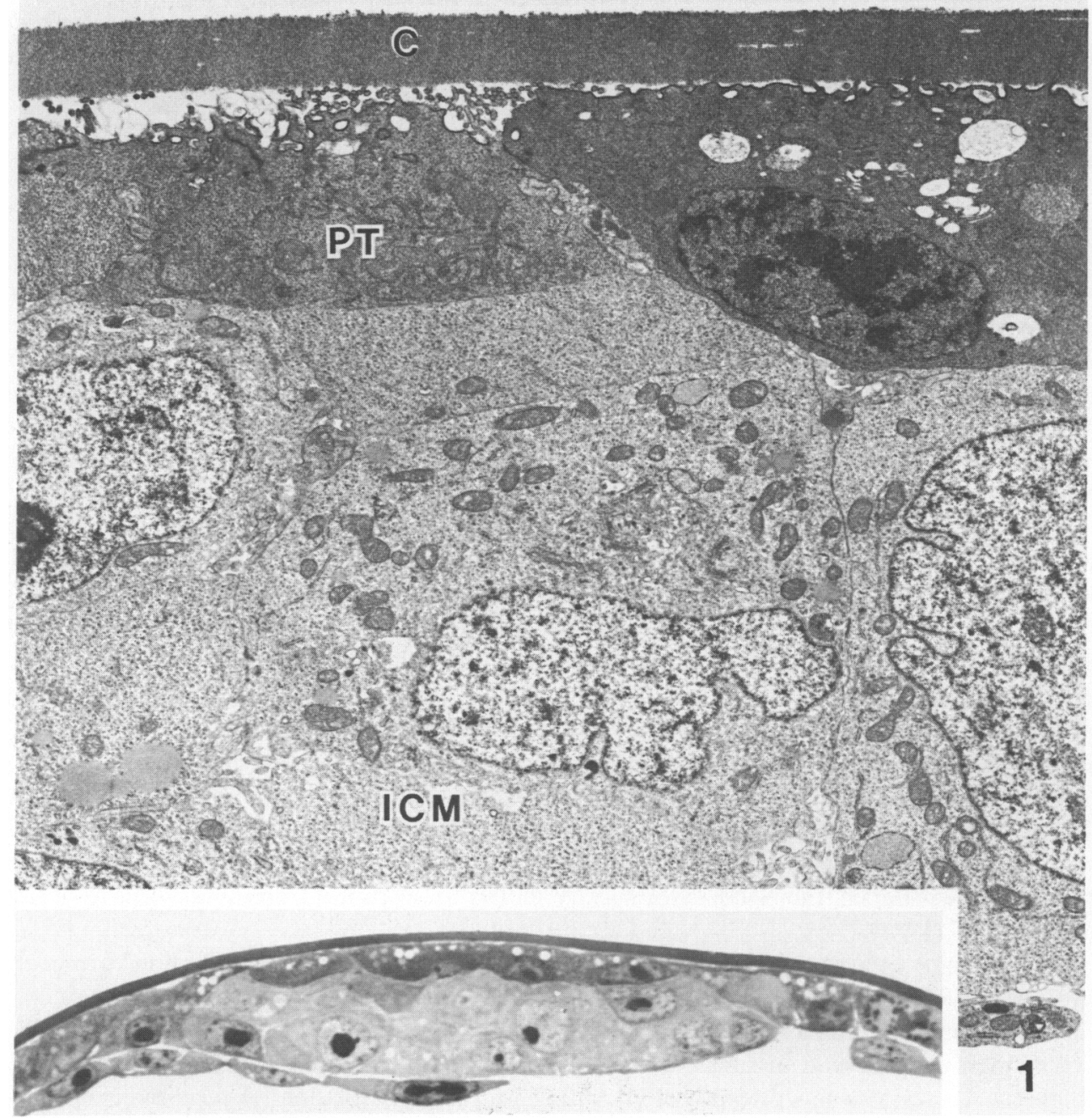

Fig. 1. An electron micrograph and light micrograph (inset) of the inner cell mass (ICM) of a horse blastocyst. Both micrographs show darker polar trophoblast cells (PT) overlying the pale inner cell mass cells. The trophoblast cells, which contain large vacuoles, are closely associated with the underlying epiblast cells. The acellular membrane is the capsule (C). Day $7,0.4 \mathrm{~mm}$, $\times 4950$; inset, $\times 710$.

Junctional complexes were often but not consistently found in basal areas of the epiblast. As in the previous stage, there were only stretches of basal laminar material associated with the epiblast, and no such materials were associated with the endoderm.

\section{Dispersion of polar trophoblast cells}

With progressive enlargement of the blastocyst from 2 to $4 \mathrm{~mm}$, the polar trophoblast cells became dispersed over the surface of the epiblast both as clusters and as individual cells (Figs 6, 7). These isolated cells retained the apical vacuoles typical of trophoblast cells, continued to share junctional complexes with the underlying and/or adjacent epiblast cells, and continued to undergo 

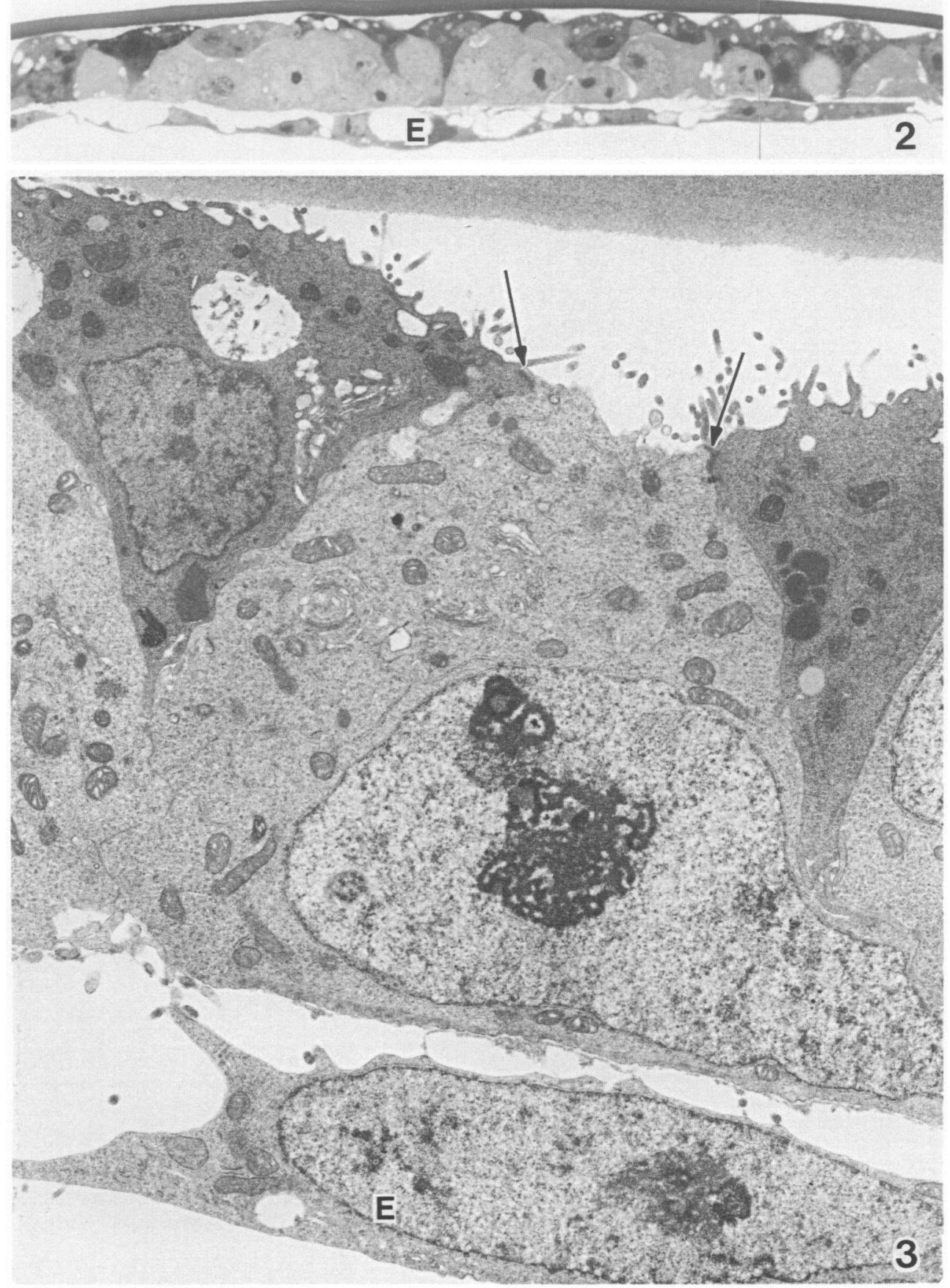

Fig. 2. With increasing growth of the blastocyst the ICM spreads, and polar trophoblast cells, rather than being fusiform in outline, are more peg-like, extending basally between the rounded epiblast cells. The endodermal layer $(\mathrm{E})$ is complete beneath the epiblast. Day $8,1.0 \mathrm{~mm}, \times 640$.

Fig. 3. An epiblast cell faces the surface between two polar trophoblast cells (arrows). The pale epiblast cell has few microvilli and pinocytotic vesicles, and no vacuoles. An incomplete basal lamina appears beneath the epiblast but not adjacent to endoderm (E). Day $8,1.5 \mathrm{~mm}, \times 8990$. 


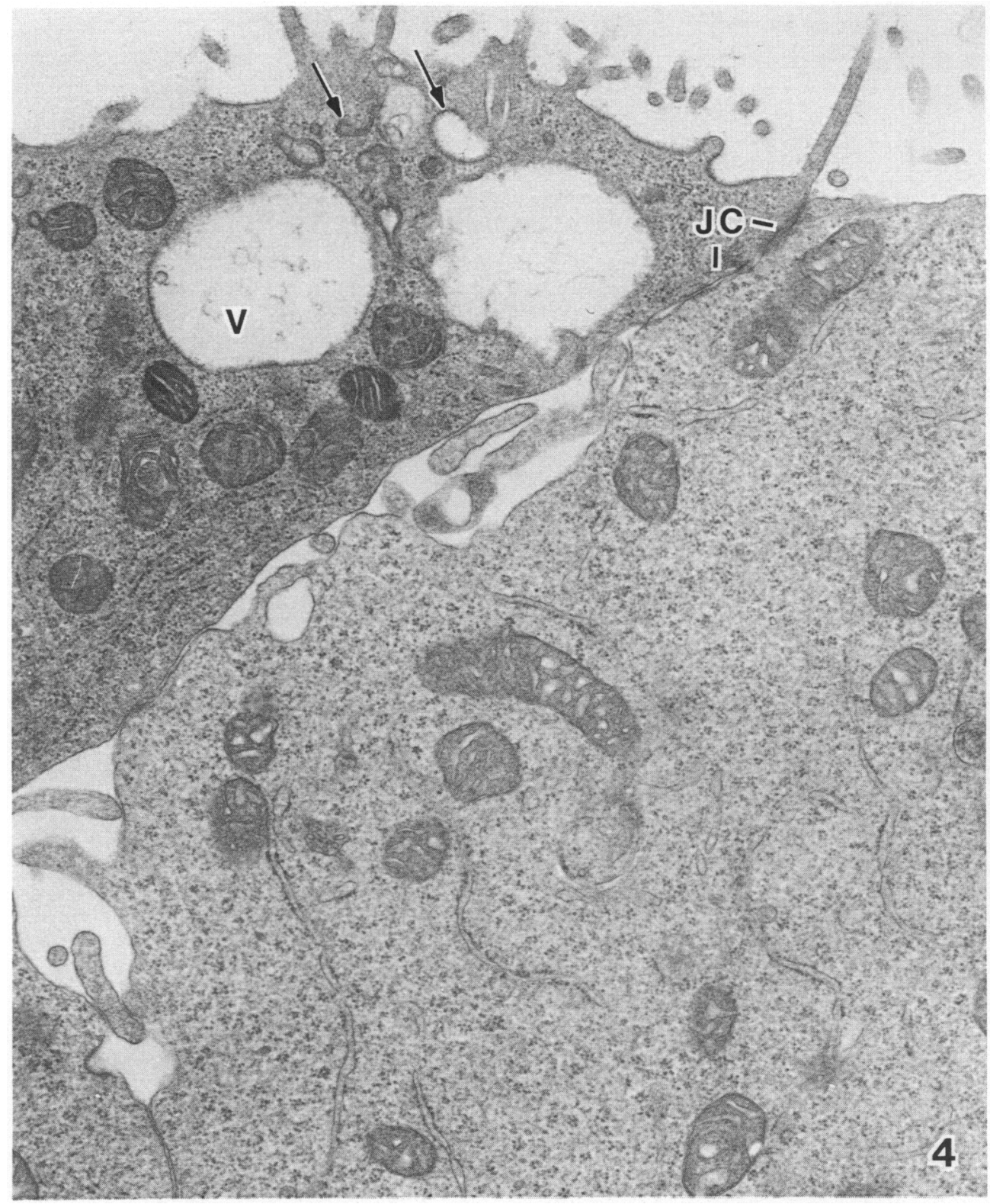

Fig. 4. Higher magnification of a polar trophoblast cell (left) sharing a junctional complex (JC) with an epiblast cell (right). The trophoblast cell has more abundant microvilli and numerous pinocytotic vesicles and tubules (arrows), in addition to large vacuoles ( $\mathrm{V}$; endosomes). Day 8 , $1.5 \mathrm{~mm}, \times 25000$.

mitosis. For at least 2 days after polar trophoblast cells became isolated (Days 9 and 10), most of these cells appeared quite healthy. However, the cells developed large irregular homogeneous granules in addition to vacuoles (Fig. 6). The granular endoplasmic reticulum, both in scattered polar trophoblast cells and in mural trophoblast, was abundant and appeared as characteristic strands with a beaded appearance, perhaps indicative of arrays of fenestrated cisternae. 


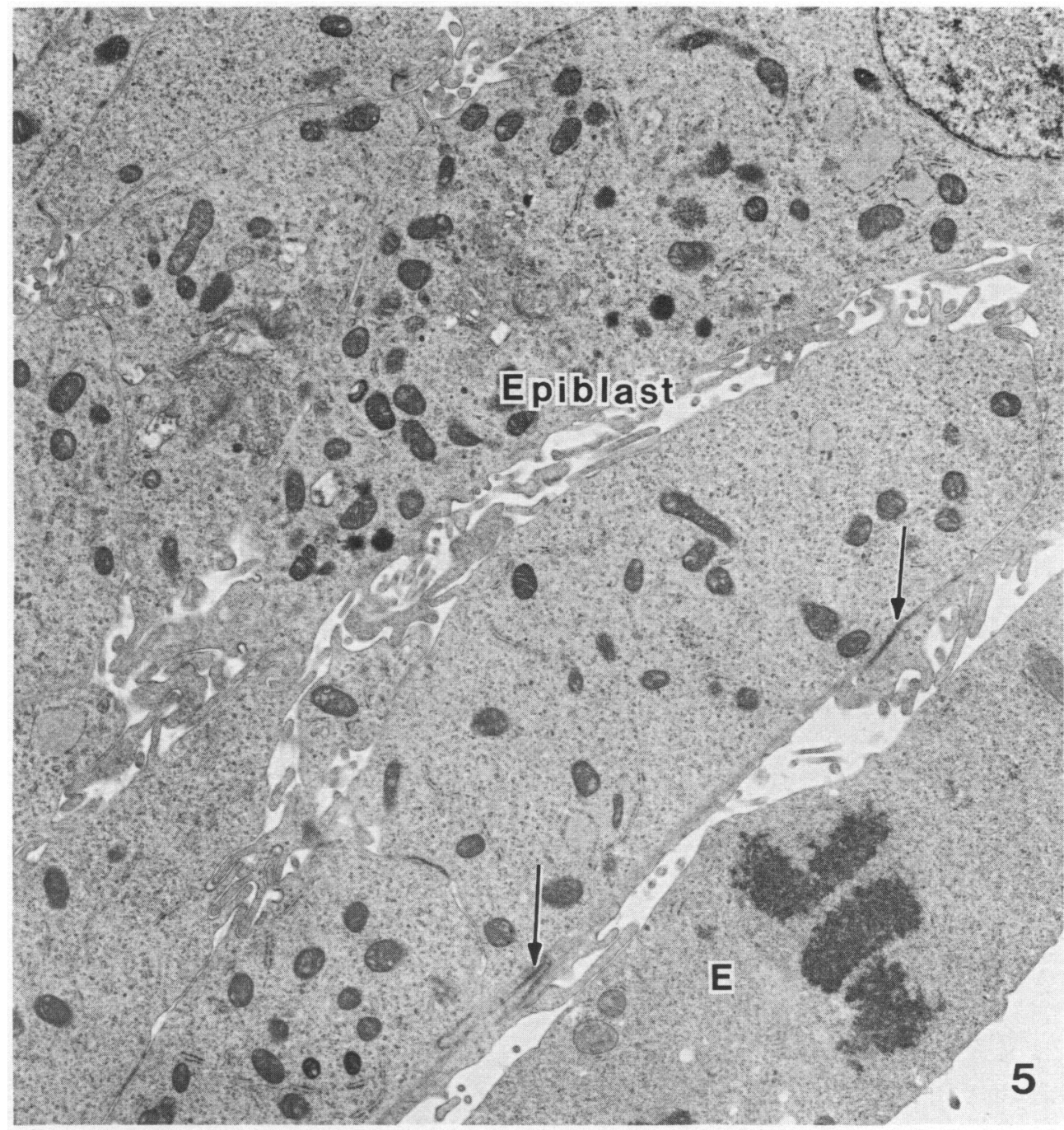

Fig. 5. Junctional complexes (arrows) are often found in the basal region of the epiblast and there are projections into intercellular spaces. E, endoderm. Day $8,1.0 \mathrm{~mm}, \times 8700$.

The epiblast portion of the ICM increased in thickness not only by elongation of some individual cells but by increased cell numbers, resulting in irregular bilaminar and multilaminar regions within the ICM (Fig. 7). The basal lamina of the epiblast remained as discontinuous patches of flocculent material, and there was no evidence that the endoderm had a basal lamina.

\section{Disappearance and fate of polar trophoblast cells}

During subsequent development of the blastocyst the ICM, while continuing to grow, also developed a large number of dense inclusions (Fig. 8). Some of the polar trophoblast cells on the surface of the ICM appeared quite healthy, but others showed evidence of deterioration such as swelling of the endoplasmic reticulum and coalescence of some of the vacuoles (Fig. 9). Their apical outlines became quite irregular. Often these cells appeared to be undergoing degeneration, with nuclear pycnosis and excessive vacuolation. Cell divisions continued to be found in the epiblast, but 


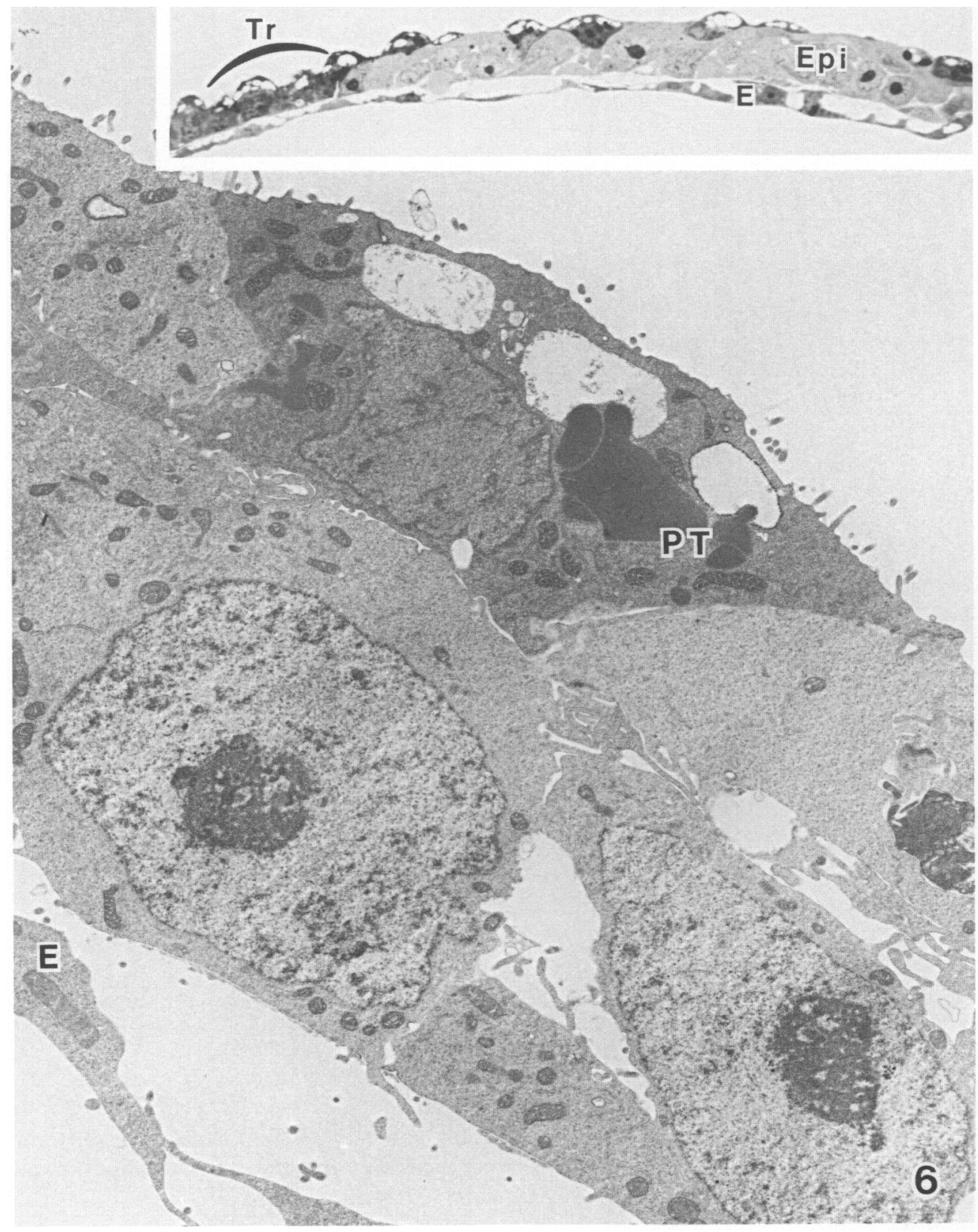

Fig. 6. This electron micrograph and light micrograph (inset) illustrate polar trophoblast cells (PT) isolated on the surface of the epiblast. The polar trophoblast cells are nevertheless readily distinguished by the presence of large vacuoles (V), but in addition have large granules (as seen in the single isolated cell shown in the electron micrograph). The basal lamina beneath the trophoblast is discontinuous. Inset: Note mural trophoblast (Tr) and continuous endodermal layer (E). Day $9,2 \cdot 0 \mathrm{~mm}, \times 6925$; inset, $\times 420$. 

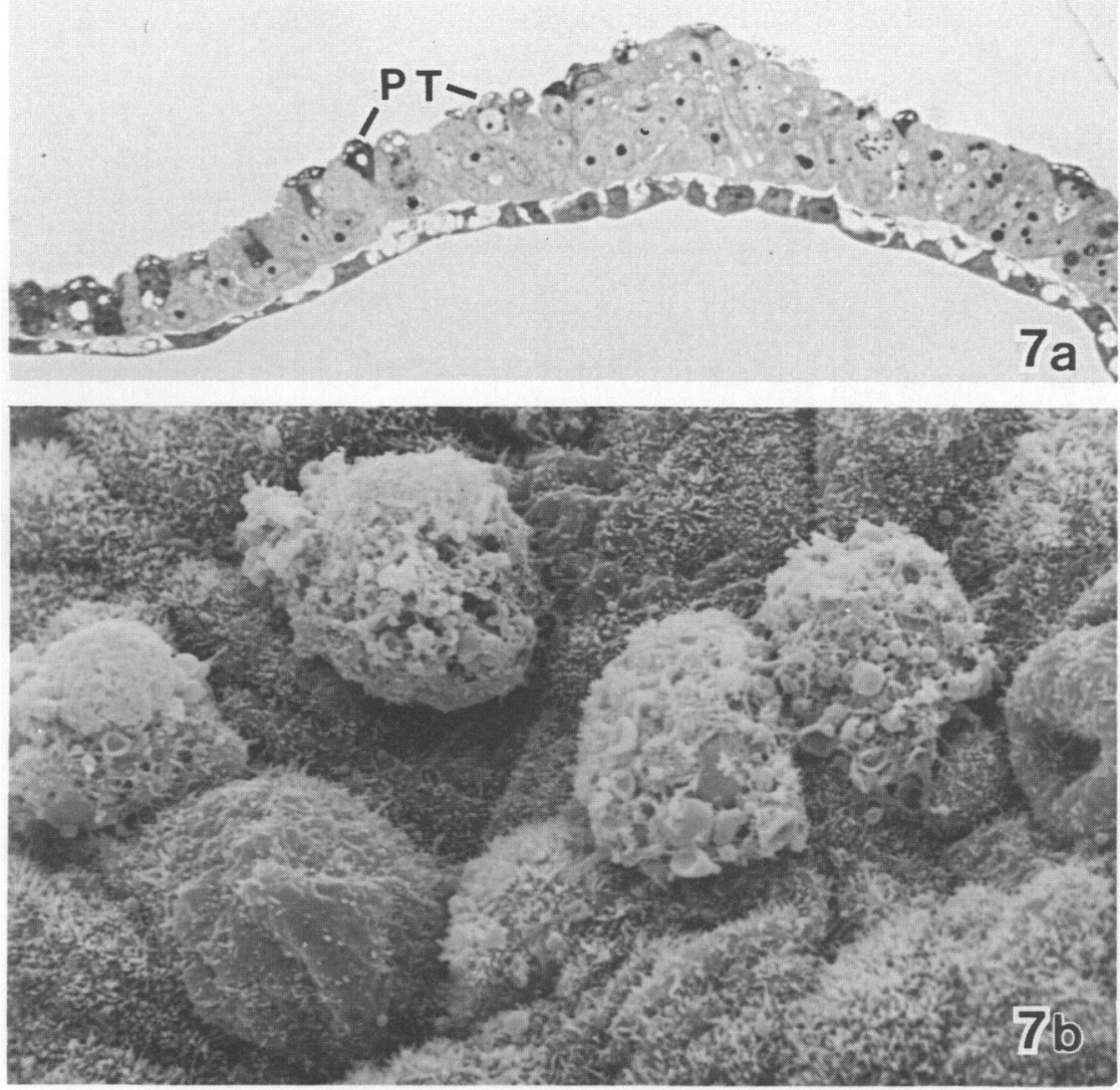

Fig. 7. Light (a) and scanning electron (b) micrographs of an ICM with scattered protruding polar trophoblast (PT) cells at the surface. The epiblast layer varies in thickness. Some damage to the cell surfaces probably occurred during preparation. Day $10,3.7 \mathrm{~mm}, \times 290$.

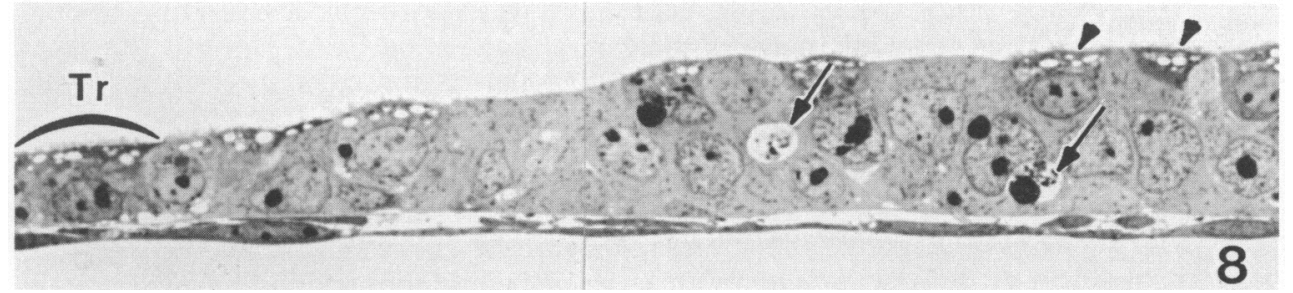

Fig. 8. ICM of a $3.7 \mathrm{~mm}$ blastocyst. In addition to scattered polar trophoblast cells with apical vacuoles (arrowheads), largé telolysosomes or phagosomes (arrows) are present in the ICM. Note the similarity of the apical regions of the mural trophoblast (Tr) and of the scattered cells overlying the epiblast. Day $11,4.5 \mathrm{~mm}, \times 640$.

mitotic figures were not seen in any polar trophoblast cells at this stage. The cells showing degenerative changes were closely associated with the underlying epiblast cells as were the apparently healthy trophoblast cells. Numerous dense telolysosomes (phagosomes) containing cell debris, including apparent cell nuclei, appeared frequently within the epiblast cells (Fig. 10). Although the 


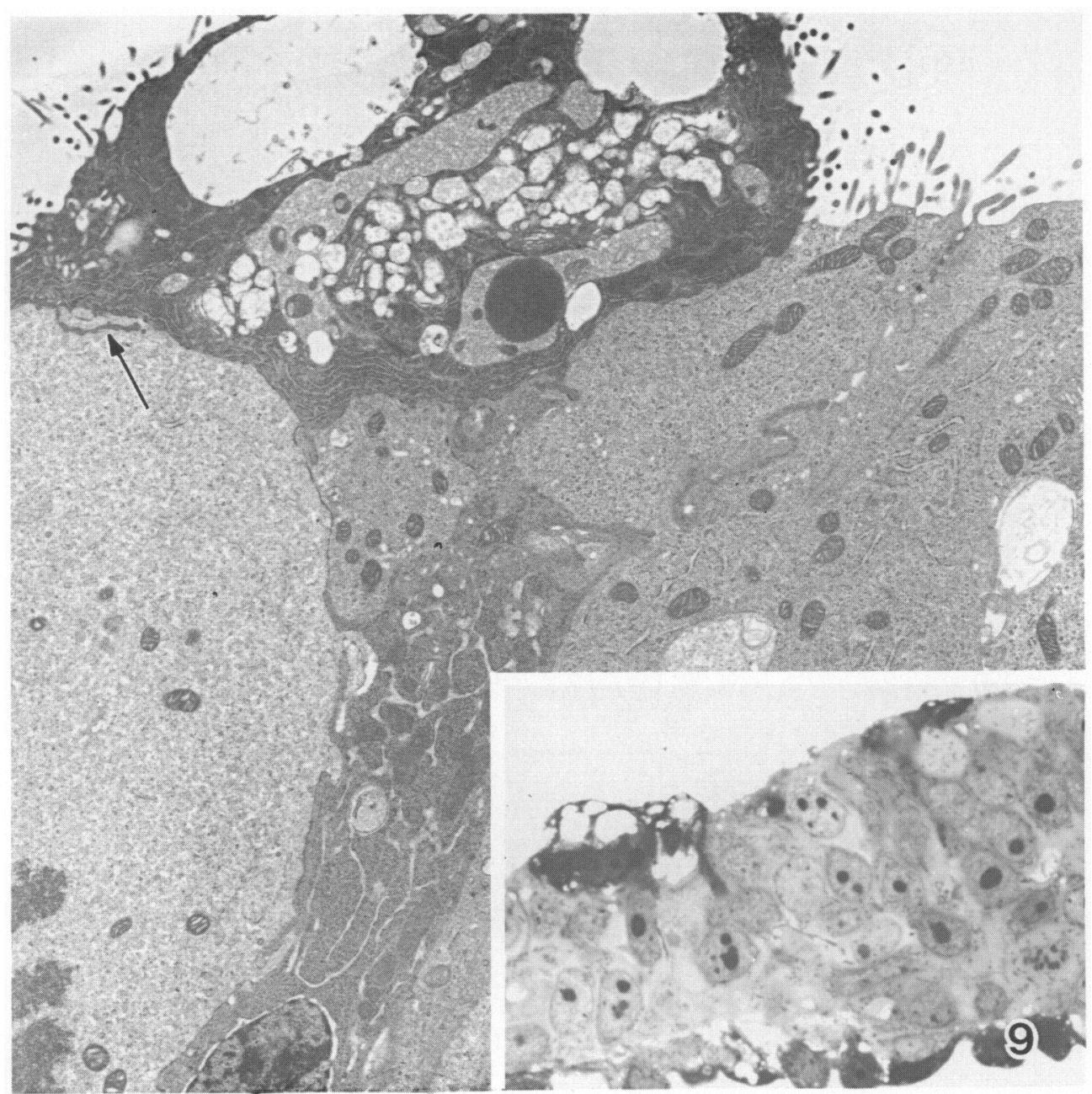

Fig. 9. Many of the scattered polar trophoblast cells now appear to be deteriorating, demonstrated by vacuolation seen both in the light micrograph and in the TEM. However, the polar trophoblast cells are still very closely associated with the underlying epiblast cells, even having projecting processes (arrow). Day $12,10 \mathrm{~mm}, \times 3960$; inset, $\times 640$.

extent of degeneration of the lysosomal contents precluded identification of cellular origin, it seems probable that some were derived from ingestion of the necrotic polar trophoblast cells.

\section{Polar and mural trophoblast cells}

When blastocysts and blastocyst fragments were incubated with cationized ferritin and peroxidase, both tracers were found in the coated pits and coated tubules. Longer exposure to peroxidase $(10-20 \mathrm{~min})$ showed that the large clear vacuoles of the mural and polar trophoblast cells were rimmed with reaction product, indicating that the peroxidase had been transferred from coated pits and tubules to these vacuoles, which were therefore part of the endocytic apparatus (Fig. 11). The membrane-bound granules did not contain reaction product in either cell type. Polar trophoblast cells, including individual cells and clusters, were endocytic until at least Day 10, but no ICM regions from blastocysts larger than $4 \mathrm{~mm}$ were examined by tracer methods. 


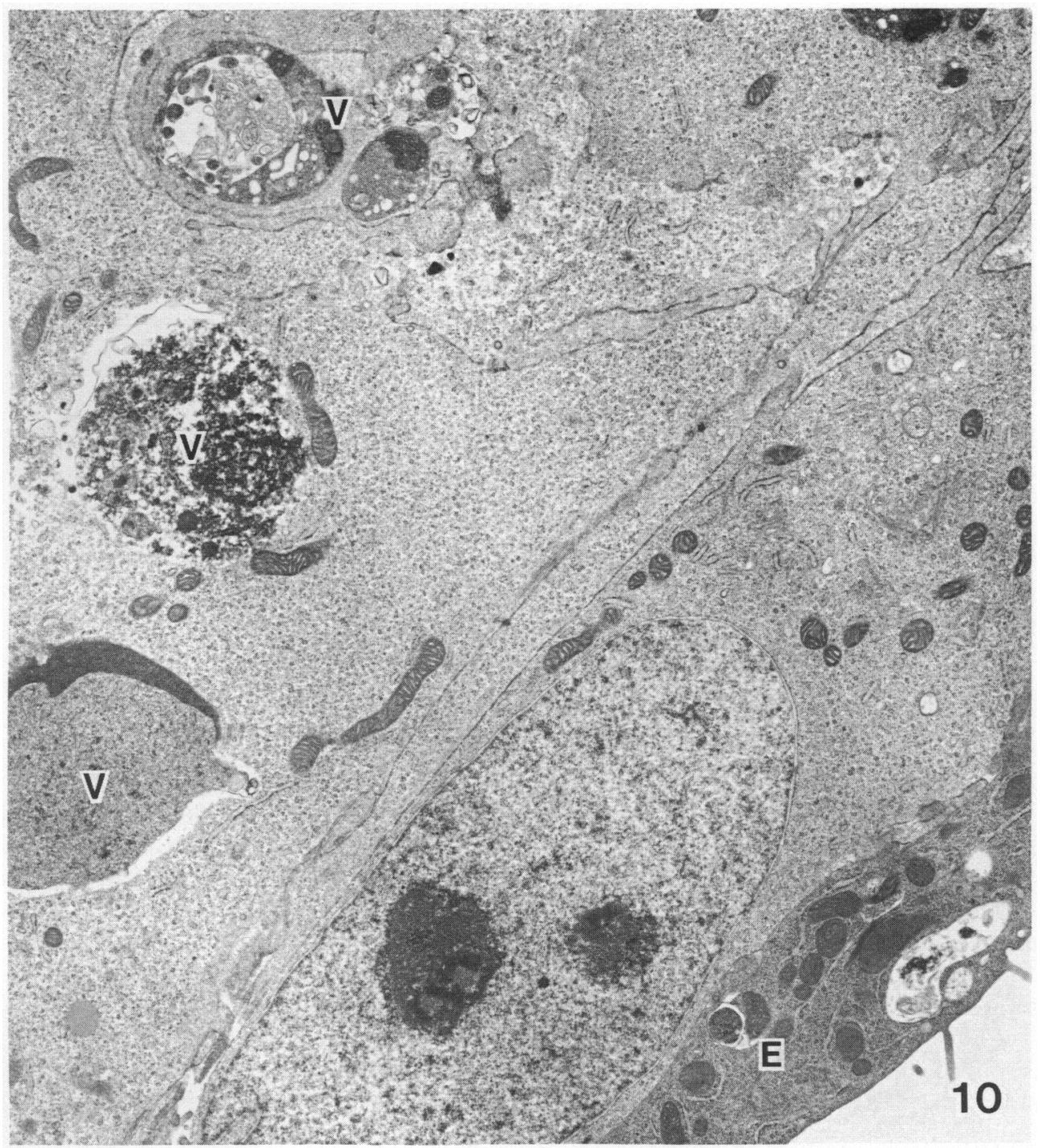

Fig. 10. Epiblast cells containing large vacuoles (V) with cell debris, probable evidence of phagocytosis of effete cells. $E=$ endodermal cell. Day $12,10 \mathrm{~mm}, \times 9860$.

\section{Discussion}

In the pig, the polar trophoblast (Rauber's layer) is complete when the blastocyst is $1 \mathrm{~mm}$ in diameter, but the inner cell mass is largely uncovered by the 3 or $4 \mathrm{~mm}$ stage (Giesert et al., 1982; Stroband et al., 1984). The scanning micrographs presented by the authors cited show that, when the polar trophoblast becomes discontinuous, it withdraws as a coherent group of cells, progressively exposing an expanding circular area of underlying epiblast cells. Occasional groups of trophoblast cells are left as temporarily intruding strands connected both to one another and to the peripheral ring of cells. Similarly, in the spotted skunk, the polar trophoblast becomes flattened before disruption, then subsequently forms a thick flange ringing the periphery of the ICM as the epiblast becomes exposed during preimplantation development (Enders et al., 1986). Although the method of exposure 


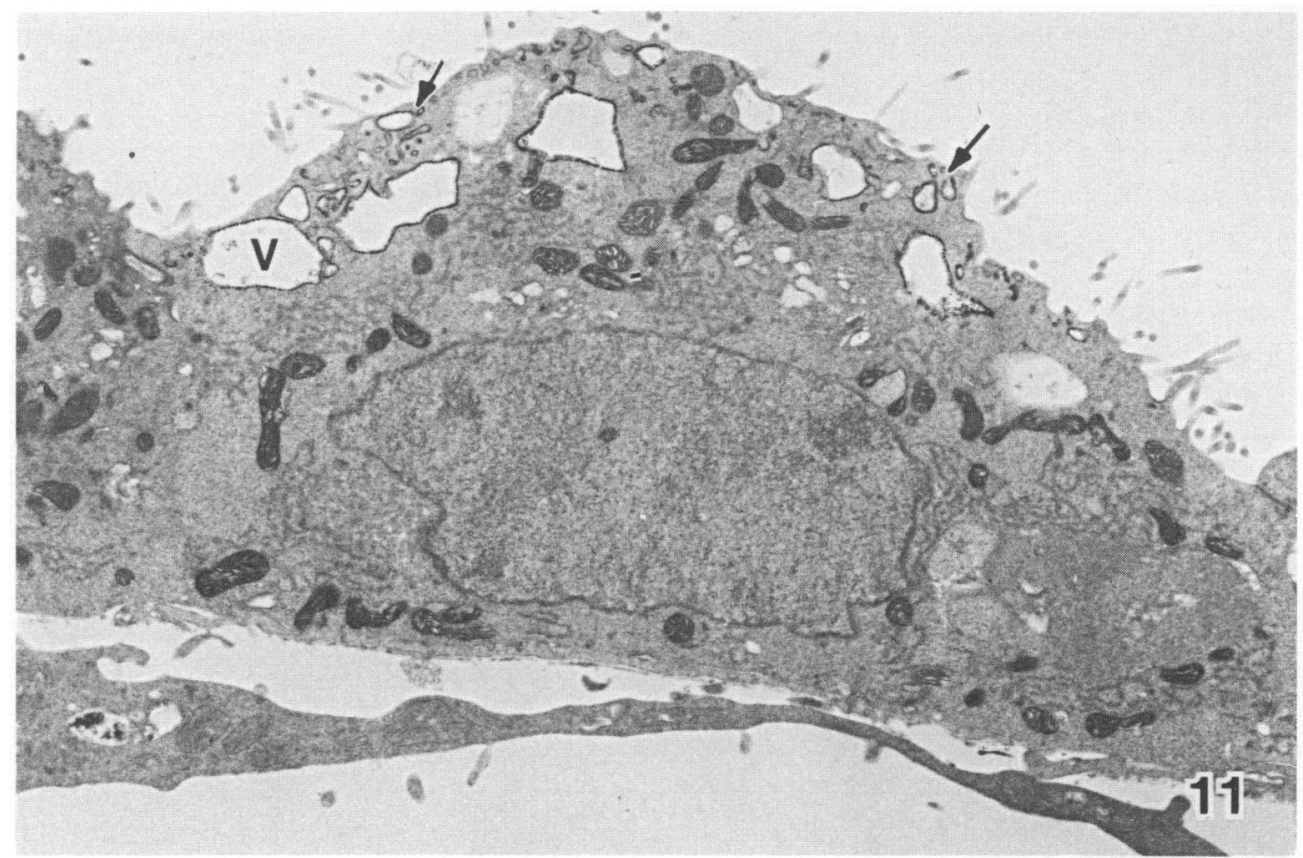

Fig. 11. Mural trophoblast, illustrating the presence of an exogenous tracer (horseradish peroxidase) in apical tubules (arrows) and vacuoles (V). Day $10,3.7 \mathrm{~mm}, \times 7000$.

of the epiblast in the cat is not known precisely, the appearance of the ICM and adjacent trophoblast after loss of Rauber's layer (Day 10 p.c., Denker $e t$ al., 1978) indicates a process similar to that of the spotted skunk. In the rabbit, as in the horse, the polar trophoblast layer becomes disrupted and individual cells remain on the surface of the ICM (B. S. Williams \& J. D. Biggers, personal communication); however, no evidence of deterioration of these cells was found and it is suggested that the cells migrate into the mural trophoblast. Blastocysts of the horse and of the rabbit are therefore similar in showing multiple disruptions of polar trophoblast and persisting isolated cells, but the horse may be unique in showing evidence of cell breakdown within the epiblast of the ICM.

From the cell morphology reported here, it appears that the polar trophoblast of the horse blastocyst becomes discontinuous while these cells are still healthy and actively dividing. The development of discontinuities in this layer without evidence of cell sloughing or of retreat to the margins of the ICM suggests that the polar trophoblast is not increasing in amount as is the underlying ICM, and that the adhesion of trophoblast cells to the underlying ICM cells is as great as or greatep than adhesion to the adjacent trophoblast cells. This preferential adhesion to the ICM would be in marked contrast to the situation in the pig and skunk, in which the polar trophoblast, after becoming disrupted over the ICM, withdraws as a coherent group of cells, suggesting greater trophoblast-to-trophoblast adhesion than trophoblast-to-epiblast adhesion.

The greater effective adhesion of trophoblast to epiblast does not necessarily imply that there is a different mechanism of adhesion between trophoblast and epiblast than between trophoblast cells. The shape of trophoblast cells is such that they share more surface with the epiblast than with adjacent trophoblast cells. Consequently, changes in cell shape may be as significant as changes in the nature of cell adhesive properties.

After the polar trophoblast becomes discontinuous, several mechanisms for removal of the polar trophoblast cells would appear possible: (1) autolysis, (2) sloughing, (3) phagocytosis by epiblast cells, and (4) migration into the blastocyst cavity or into mural trophoblast. Although there was little evidence of individual polar cell disintegration in situ, it is still possible that rapid 
autolysis of a few cells may contribute to the loss of polar trophoblast. No evidence of cells trapped between the blastocyst and capsule was found, nor was this area a focus of cell debris. Consequently loss by sloughing into the subcapsular space is doubtful. The absence of trophoblast cells in the blastocyst cavity or between the epiblast and endoderm argues against migration of trophoblast cells through the endoderm to be sloughed into the blastocyst cavity. Moreover, the presence of numerous telolysosomes in the epiblast at the time when the polar trophoblast cells are disappearing strongly suggests that these cells are ingesting cells or cell debris. Although the debris may come from epiblast cells as well as polar trophoblast cells, it suggests that polar trophoblast cells that become apoptotic or necrotic would be phagocytosed. The development of marked adherence of polar trophoblast to the ICM could well be a major factor in the initial rapid change in shape of polar trophoblast cells, their becoming scattered when the ICM expands, and their phagocytosis rather than sloughing when they eventually become effete. While there was no marginal concentration of the individual polar trophoblast cells to suggest migration to this position, it is possible that a few cells that were originally in a marginal position might become incorporated into the mural trophoblast layer.

Cells in the polar region of horse blastocysts maintain an intact external surface despite the loss of integrity of the polar trophoblast. That is, healthy cells of the trophoblast and ICM retain close adherence and apical junctions during the cellular movements and modifications that are occurring in these stages. It was more surprising, however, to see the junctional areas at the basal region of the ICM cells. These junctions, which were never sufficiently zonular to form a complete intercellular barrier, nevertheless occasionally had the appearance of tight junctions. Desmosomes were always small and gap junctions were both rare and not very extensive when found. Nevertheless, the multiple junctions may aid in keeping the epiblast compact and might retard intercellular diffusion. Certainly there is no decrease in the rate of blastocyst expansion with disruption of the polar trophoblast and therefore no apparent increase in permeability.

During the time that the polar trophoblast becomes discontinuous over the ICM, and consequently appears to be falling behind in cell replication, the blastocyst is increasing in size in a linear fashion (Betteridge et al., 1982). The increase in size is not a result of increase in area occupied by individual mural trophoblast cells, since these cells remain cuboidal to columnar even in the largest blastocyst. Consequently, the failure of the polar trophoblast to remain an intact expanding cell layer can be considered to be a result of trophoblast response to the underlying ICM. That the ICM can influence the overlying cells has been demonstrated experimentally by Gardner (1983), in relationship to inhibition of giant cell formation and stimulation of mitotic activity of mural trophoblast cells. Given \& Weitlauf $(1981,1982)$ also demonstrated that the ICM has an apparent effect on DNA synthesis during blastocyst activation after delayed implantation and in vitro. These authors found that, in the activated mouse blastocyst, the trophoblast cells in closest association with the ICM were the earliest to incorporate thymidine. A reverse effect might be postulated for the ICM of the horse blastocyst at this stage, which may diminish the rate of replication of polar trophoblast cells.

This research was supported in part by grant HD 10342 from the National Institute of Child Health and Human Development, by the Equine Research Laboratory, School of Veterinary Medicine, and by the Oak Tree Racing Association.

\section{References}

Allen, W.R., Hamilton, D.W. \& Moor, R.M. (1973) The origin of equine endometrial cups. II. Invasion of the endometrium by trophoblast. Anat. Rec. 177, 485-501.

Betteridge, K.J. \& Guillomot, M. (1982) Scanning electron microscopy of preattachment horse embryos. $J$. Reprod. Fert., Suppl. 32, 623, Abstr.
Betteridge, K.J., Eaglesome, M.D., Mitchell, D., Flood, P.F. \& Beriault, R. (1982) Development of horse embryos up to twenty two days after ovulation: observations on fresh specimens. J. Anat. 135, 191-209. 
Bousquet, D., Guillomot, M. \& Betteridge, K.J. (1987) Equine zona pellucida and capsule: some physicochemical and antigenic properties. Gamete Res. 16, 121-132.

Cruz, Y.P. \& Pedersen, R.A. (1985) Cell fate in the polar trophectoderm of mouse blastocysts as studied by microinjection of cell lineage tracers. Devl Biol. 112, 73-83.

Denker, H.E., Eng, L.A., Mootz, U. \& Hamner, C.E. (1978) Studies on the early development and implantation in the cat. I. Cleavage and blastocyst formation. Anat. Anz. 144, 457-468.

Enders, A.C. \& Liu, I.K.M. (1987) Inner cell masstrophoblast relationships during blastocyst expansion in the horse. Anat. Rec. 218, 42A, Abstr.

Enders, A.C. \& Schlafke, S. (1986) Implantation in nonhuman primates and in the human. In Comparative Primate Biology, Vol. 3: Reproduction and Development, pp. 291-310. Eds W. R. Dukelow \& J. Erwin. Alan R. Liss, Inc., New York.

Enders, A.C., Schlafke, S., Hubbard, N.E. \& Mead, R.A. (1986) Morphological changes in the blastocyst of the Western spotted skunk during activation from delayed implantation. Biol. Reprod. 34, 423-437.

Flood, P.F. (1975) The pre-attachment horse embryo: the structure of its capsule and histochemical evidence of steroid metabolism. Information Vet. 18, 36-38.

Flood, P.F., Betteridge, K.J. \& Diocee, M.S. (1982) Transmission electron microscopy of horse embryos 3-16 days after ovulation. J. Reprod. Fert., Suppl. 32, 319-327.

Gardner, R.L. (1983) Origin and differentiation of extraembryonic tissues in the mouse. Int. Rev. exp. Path. 24, 63-133.

Giesert, R.D., Brookbank, J.W., Roberts, R.M. \& Bazer, F.W. (1982) Establishment of pregnancy in the pig: II. Cellular remodeling of the porcine blastocyst during elongation on day 12 of pregnancy. Biol. Reprod. 27, 941-955.
Ginther, O.J. (1983) Mobility of the early equine conceptus. Theriogenology 19, 603-611.

Given, R.L. \& Weitlauf, H.M. (1981) Resumption of DNA synthesis during activation of delayed implanting mouse blastocysts. J. exp. Zool. 218, 253-259.

Given, R.L. \& Weitlauf, H.M. (1982) Resumption of DNA synthesis in delayed implantation mouse blastocysts during activation in vitro. J. exp. Zool. 224, 111-114.

Goff, A.K., Renard, A. \& Betteridge, K.J. (1983) Regulation of steroid synthesis in pre-attachment equine embryos. Biol. Reprod. 28, Suppl. 1, 137, Abstr.

Hamilton, W.J. \& Mossman, H.W. (1972) Human Embryology, 4th edn. Williams \& Wikins Co., Baltimore.

Heap, R.B., Hamon, M. \& Allen, W.R. (1982) Studies on oestrogen synthesis by the preimplantation equine conceptus. J. Reprod. Fert., Suppl. 32, 343-352.

Hinrichs, K., Sertich, P.L., Palmer, E. \& Kenney, R.M. (1987) Establishment and maintenance of pregnancy after embryo transfer in ovariectomized mares treated with progesterone. J. Reprod. Fert. 80, 395-401.

Imel, K.J., Squire, E.L., Elsden, R.P. \& Shidler, R.K. (1981) Collection and transfer of equine embryos. $J$. Am. vet. med. Assoc. 179, 987-992.

Mossman, H.W. (1937) Comparative morphogenesis of the fetal membranes and accessory uterine structures. Contrib. Embryol. Carneg. Instn 26, 129-246.

Oguri, N. \& Tsutsumi, Y. (1972) Non-surgical recovery of equine eggs, and an attempt at non-surgical egg transfer in horses. J. Reprod. Fert. 31, 187-195.

Stroband, H.W.J., Taverne, N. \& Bogaard, M.V.D. (1984) The pig blastocyst: its ultrastructure and the uptake of protein macromolecules. Cell Tissue Res. 235, 347-356.

Van Niekerk, C.H. \& Allen, W.R. (1975) Early embryonic development in the horse. J. Reprod. Fert., Suppl. 23, 495-498.

Received 6 October 1987 